\title{
Medical Microbiology
}

RESEARCH ARTICLE

\section{Prevalence of Vaginal Infections in Women under Screening to HPV Infection and Cervical Lesions in Brazilian Basic Health Service}

\author{
Emanuella Francisco Fajardo ${ }^{1}$, Gabriela Roberta Braz ${ }^{1}$, Mara Rosa ${ }^{1}$, Tatiane Marques ${ }^{1}$, \\ Bruno Belmonte Martinelli Gomes,2, Thiago Mantello Bianco ${ }^{3}$, Ana Karina Marques \\ Salge ${ }^{4}$, Dayana Pousa Siqueira Abrahao ${ }^{1}$, Eduardo Elias Vieira de Carvalho ${ }^{5}$, George \\ Kemil Abdalla and Douglas Reis Abdalla ${ }^{1 *}$
}

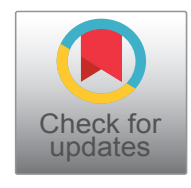

${ }^{1}$ Department of Health Science, Faculty of Human Talent, Minas Gerais, Brazil

${ }^{2}$ Department of Celular and Molecular Biology, Medicine Faculty of Ribeirão Preto, São Paulo, Brazil

${ }^{3}$ Department of Clinical Oncology, Stem Cells and Celular Therapy, Medicine Faculty of Ribeirão Preto, São Paulo, Brazil

${ }^{4}$ Federal University of Goiás, Goiás, Brazil

${ }^{5}$ Department of Applied Physical Therapy, Institute of Health Sciences, Federal University of Triângulo Mineiro, Minas Gerais, Brazil

*Corresponding author: Douglas Reis Abdalla, Faculty of Human Talent, Department of Applied Physical Therapy, Institute of Health Sciences, Av. Tonico dos Santos, 333, São Cristóvão, Zip Code: 38100-000, Uberaba, Minas Gerais, Brazil, Tel: 55-34-3311-7400

\begin{abstract}
Introduction: Vaginal infections and inflammations are responsible for the most demand at gynaecology, because the main complains are leucorrhea and vulvovaginitis, there is a specifically interest in cervix cancer prevention.

Aim: The aim of this study is to understand the prevalence of vaginal infections cases and cervical lesions, found in women attended at health basic units from Igarapava, São Paulo state, Brazil.

Methods: There were analyzed retrospectively 1,071 cases of cytopathological exams from SUS (Brazilian Unique System of Health) during the period of January 2013 to July 2016, patients from Igarapava city, São Paulo state.

Results: Gardnerella vaginalis was the most commonly found microorganism in the four years studied with the highest prevalence in 2014 with $46.8 \%$. This study identified that all cases of Gardnerella vaginalis are associated with Mobiluncus sp. Candida sp should decrease gradually over the years, in $2013(36.9 \%)$ and $2016(16.9 \%)$, as well as the decrease of normal bacterial flora (Lactobacillus) with $11 \%$ only in 2016 . Trichomonas vaginalis should increase in $2016(37.5 \%)$ compared to $2014(31.2 \%)$, and finally just found two cases of cervical intraepithelial neoplasia grade I. Conclusion: In view of the values obtained from bacterial, fungal and protozoal genital infections, there is a need for
\end{abstract}

a better follow-up of the women screened, both in terms of prevention of these infections, as well as infections related to the development of tumors, knowledge of the signs and symptoms of these infections, as well as specialization courses for professionals to better assist these women, in order to guarantee health and quality of life.

\section{Keywords}

Genital infections, Women's health, Public health

\section{Introduction}

Cytopathological exam of the cervical membrane, known as Papanicolaou, was adopted at fifties, as a method which can identify pre-cancerous lesions [1] and consists at observation of exfoliated sloughed off cells from external (ectocervix) and internal (endocervix) part of cervix [2].

More than ever, Papanicolaou has been helping at inflammation and infections detections of the feminine genital tract, evaluating the intensity and the possible etiological causes $[3,4]$.

According to Brazilian Health Ministry the exam must

Citation: Fajardo EF, Braz GR, Rosa M, Marques T, Gomes BBM, et al. (2018) Prevalence of Vaginal Infections in Women under Screening to HPV Infection and Cervical Lesions in Brazilian Basic Health Service. Int Arch Med Microbiol 1:006.

Accepted: October 04, 2018; Published: October 06, 2018

Copyright: (c) 2018 Fajardo EF, et al. This is an open-access article distributed under the terms of the Creative Commons Attribution License, which permits unrestricted use, distribution, and reproduction in any medium, provided the original author and source are credited. 
be conducted in women with age between 25 and 60 years old and sexually active women each three years, after two negative results with one year range [5].

Genital infections and inflammations are responsible for the most demand at gynecology, because the main complains are leucorrhea and vulvovaginitis, there is not a specifically interest in cervix cancer prevention [6].

Vaginal infections are any disease that affects the feminine genital caused by several microorganisms. The most frequents are candidiasis, trichomoniasis, Gardnerella vaginalis, Gonococcus and Chlamydia infections, although Gonococcus and Chlamydia are more related to cervical infections. They can cause simple or grave infections, causing inflammatory cervix disease, cervical cancer, infertility, spontaneous miscarriage and ectopical pregnancy, which can lead to maternal obit [7].

Candida sp. can cause pruritus, dyspareunia, vaginal discharge with whitish color, swollen vulva and vagina, hyperemia, and it can or not cause burning and stinging when urinate [8]. Gardnerella vaginalis is characterized by grayish discharge with foul-smelling, without local irritation [9], and Trichomonas vaginalis presents variate symptoms depending of clinical patient conditions and the number of infecting parasites [10].

The presence of microorganisms in the vagina are determined by factors that alter their survival capacity, including vaginal $\mathrm{pH}$, quantity of glycogen for bacteria metabolism, that helps the colonization of pathogenical microorganisms. Several external factors are related to the normal microbiota susceptibility, such as: use of wide spectra antibiotic, period, post-coital, excitation (production of transudate that elevates the vaginal $\mathrm{pH})$, immunosuppression by chemotherapeutic agents, glucocorticoids, immunosuppresses, HIV, menopause, decompensated diabetes, use of vaginal shower, IUD, tie clothes, use of internal absorbent (that cause bacteria proliferation when used for more time than recommended), wrong hygiene habits, pregnancy, trauma after sexual act, oral hormonal contraceptive of high dosage and unprotected sexual relationships [11].

According to Campos, et al. [12], alkaline pH of the vagina is a predisposition for the appearance of HPV genital infections, which is a condition directly related to the neoplasia emerge. $\mathrm{pH}$ changes for values higher than 4.5 are easily found in women who presents bacterial vaginosis, being the immunological response in this case and for HPV infection are similar, with an expressive increase of cytokines for both. In this sense many studies in the literature abording immune response in different grades of cervical lesions, thus understanding how the immune system behaviour during HPV infection with or without vaginosis [13].

Thus, because of the clinical importance for women well-being and health, and improve their knowledge about HPV infection and cervical lesions and cancer development, as report in the literature $[14,15]$. In this sense, the present study aimed to verify the prevalence of microorganisms that are normally found in the vaginal and cervical microbiota, in addition to verify the prevalence of agents that cause infections e lesions in vaginal and cervical in women attended to basic health units of Igarapava, SP, Brazil.

\section{Methods}

There were analyzed retrospectively 1,071 cases of cytopathological exams from SUS (Brazilian Unique System of Health) during the period of January 2013 to July 2016, patients from Igarapava city, Sao Paulo state, which presents a population of 25,950 citizens, being 12,762 men and 13,163 women. The evaluated populational sample corresponds to $8.14 \%$ of feminine people, being 6807 (51.7\%) women between 25 and 60 years of age. This study was approved by the Research Ethics Committee from the Faculty of Human Talent, Uberaba, Minas Gerais, Brazil, under the protocol number 0060/2016.

Cervicovaginal samples were analyzed by Cancer Hospital of Barretos, that has an agreement with Igarapava city. Cytological samples were obtained by collecting cervix-vaginal material performed with the help of an Ayre and cytobrush spatula, or only vaginally for hysterectomized patients. After fixation of the material, the smears were stained by the Papanicolaou method and analyzed under an optical microscope in increments of 100X and 400X, and possibly 1000X for confirmation of the microorganisms. The results were expressed according to the Bethesda System.

Data were obtained from database of Municipal Secretary of Health from Igarapava, São Paulo state, where all the information about the exams was collected, such as age of the volunteer and year of sampling. All the women with insufficient sample for analysis were discarded, including all the ages. The therapeutic conducts performed by the medical team were not reported in the database.

The different variables obtained information from the database were tested for normal distribution. When distribution was non normal, nonparametric tests were performed, test of Kruskal-Wallis test, and Dunn's Multiple Comparison Test. The results were expressed as medians and interquartile range (IQR). Proportions were compared using the $\mathrm{X}^{2}$ test (chi-square), when necessary, by Fisher's exact test. The observed differences were considered significant when the probability of rejection of the null hypothesis is less than 0.05 (5\%).

\section{Results}

The studied population was formed by 1,071 women, with different ages. The results found were divided into six groups, being them composed by women who presented different infections: Gardnerella vaginalis, 
Candida sp., Trichomonas vaginalis, normal flora (Lactobacillus), presence of coccus and bacillus. The groups are presented at Table 1.

The average age of the patients was 38.9 years old, being 38.5 years old in 2013, 38.7 in 2014, 40.8 in 2015 and 37.7 in 2016 (Table 2). The age range who performed cytopathological exam the most was 15 to 30 years, with statistical significance. Gardnerella vaginalis was the most prevalent, affecting a total of 154 women, followed by Candida sp, affecting 65 women (Table 3).

The year with highest prevalence of Gardnerella vaginalis was 2014 (46.8\%), while women presenting normal flora was $36.1 \%$. In 2015 there was a number decrease of Gardnerella vaginalis infection cases (11.7\%), being $7.1 \%$ in 2016 . Candida sp. infections were $36.9 \%$ in 2013 , decreasing to $30.8 \%$ in 2014 and to $16.9 \%$ in 2016. Trichomonas vaginalis infections presented the lowest rate found in women, being only 16 cases found

Table 1: Distribution of the infectious agents registered in the cytological examination of the uterine cervix.

\begin{tabular}{|l|l|l|}
\hline Infectant Agent & Negative $\mathbf{n ~ ( \% )}$ & Positive n (\%) \\
\hline Lactobacillus & $451(42.1)$ & $620(57.9)$ \\
\hline Bacillus & $825(77.0)$ & $246(23.0)$ \\
\hline Coccus & $672(62.7)$ & $399(37.3)$ \\
\hline Candida & $1006(93.9)$ & $65(6.1)$ \\
\hline Gardnerella & $917(85.6)$ & $154(14.4)$ \\
\hline Tricomonas & $1055(98.5)$ & $16(1.5)$ \\
\hline
\end{tabular}

Table 2: Representation of medians and interquartile range (IQR), as well as the representation of means and standard deviations (SD)

\begin{tabular}{|l|l|l|l|}
\hline Year & Median (IQR) & Mean (SD) & p-value \\
\hline 2013 & $38(26)$ & $38.5(15.7)$ & 0.2452 \\
\hline 2014 & $37(24)$ & $38.7(15.1)$ & \\
\hline 2015 & $38(28.5)$ & $40.8(16.3)$ & \\
\hline 2016 & $35(31)$ & $37.7(15.8)$ & \\
\cline { 1 - 2 } & & &
\end{tabular}

Note: performed statistical test of Kruskal-Wallis test and Dunn's Multiple Comparison Test. during the years analyzed, being the highest prevalence found in 2016 with $37.5 \%$. Lactobacillus were found in 620 women during the four years, but it has no clinical significance because vaginal flora is composed mostly by them (Table 4).

There were found bacillus in 246 women, with highest prevalence in $2014(50 \%)$ and coccus were found in 399 women, with highest prevalence in 2013 (71.4\%). They are normal components of vaginal ecosystem ( $\mathrm{Ta}$ ble 4). All the women infected with Gardnerella vaginalis presented associated bacillus.

Regarding to cervical intraepithelial neoplasia, just two cases has been reported in the database.

\section{Discussion}

Vaginal infections are characterized by vaginal flora modifications, where the flora mostly compound by Lactobacillus is substituted by other etiological agents [16].

In this study, we observed the high prevalence of infections by Gardnerella vaginalis, especially during the year of 2014. The results are similar to the ones found in other studies, such as the one described by Coser, Rodrigues [17], where they found high prevalence of Gardnerella vaginalis. According to Silveira, et al. [18], this bacterium is the cause of $90 \%$ of asymptomatic vaginal infections. Mitra, et al. [19] also reported that this bacterium is common in women during their fertile age, occurring due to an increased vaginal microbiota proliferation.

Candidiasis in an infection caused by a commensal fungus. In this study, it was the second most prevalent infection, the opposite of found by Ribeiro, et al. [20], who found Candida sp. as the main microorganism, found in $54.3 \%$ of the studied population. The age range is according to Boatto, et al. [21], who found the prevalence in women of 18 to 34 years old; it is according to

Table 3: Distribution of infectious agents registered in the cervical cytology exam in each age class interval.

\begin{tabular}{|l|l|l|l|l|l|l|l|}
\hline Age Class & $\begin{array}{l}\text { Number of people } \\
\text { tested }\end{array}$ & $\begin{array}{l}\text { Lactobacillus } \\
\mathbf{n}(\mathbf{\%})\end{array}$ & $\begin{array}{l}\text { Bacillus } \\
\mathbf{n}(\mathbf{\%})\end{array}$ & $\begin{array}{l}\text { Coccus } \\
\mathbf{n}(\mathbf{\%})\end{array}$ & $\begin{array}{l}\text { Candida } \\
\mathbf{n}(\%)\end{array}$ & $\begin{array}{l}\text { Gardnerella } \\
\mathbf{n}(\%)\end{array}$ & $\begin{array}{l}\text { Tricomonas } \\
\mathbf{n}(\%)\end{array}$ \\
\hline < 14 years & $14(1.30)$ & $8(1.3)$ & $3(1.2)$ & $6(1.5)$ & $1(1.5)$ & $1(0.6)$ & $0(0.0)$ \\
\hline $\mathbf{1 5 - 3 0}$ years & $123(11.5)$ & $222(35.8)$ & $104(42.3)$ & $113(28.3)$ & $31(47.7)$ & $63(40.9)$ & $6(37.5)$ \\
\hline $\mathbf{3 1 - 4 5}$ years & $456(42.6)$ & $210(33.9)$ & $75(30.5)$ & $100(25.1)$ & $21(32.3)$ & $53(34.4)$ & $5(31.2)$ \\
\hline $\mathbf{4 6 - 6 0}$ years & $365(34.1)$ & $136(21.9)$ & $52(21.1)$ & $115(28.8)$ & $10(15.4)$ & $34(22.1)$ & $4(25.0)$ \\
\hline > 60 years & $113(10.5)$ & $44(7.1)$ & $12(4.9)$ & $65(16.3)$ & $2(3.1)$ & $3(1.9)$ & $1(6.2)$ \\
\hline Total & $\mathbf{1 0 7 1 ( 1 0 0 )}$ & $\mathbf{6 2 0 ( 1 0 0 . 0 )}$ & $\mathbf{2 4 6 ( 1 0 0 . 0 )}$ & $\mathbf{3 9 9 ( 1 0 0 . 0 )}$ & $\mathbf{6 5 ( 1 0 0 . 0 )}$ & $\mathbf{1 5 4 ( 1 0 0 . 0 )}$ & $\mathbf{1 6 ( 1 0 0 . 0 )}$ \\
\hline p-value & & $\mathbf{0 . 0 0 0 1}$ & $\mathbf{0 . 0 0 1}$ & $\mathbf{0 . 0 0 0 1}$ & 0.109 & $\mathbf{0 . 0 0 1}$ & 0.664 \\
\hline
\end{tabular}

Table 4: Distribution of infectious agents. No cytological examination of the uterine cervix in year of occurrence records.

\begin{tabular}{|l|l|l|l|l|l|l|l|}
\hline Ano & $\begin{array}{l}\text { Number of } \\
\text { people tested }\end{array}$ & $\begin{array}{l}\text { Lactobacillus } \\
\mathbf{n}(\mathbf{\%})\end{array}$ & $\begin{array}{l}\text { Bacillus } \\
\mathbf{n}(\mathbf{\%})\end{array}$ & $\begin{array}{l}\text { Coccus } \\
\mathbf{n}(\mathbf{\%})\end{array}$ & $\begin{array}{l}\text { Candida } \\
\mathbf{n}(\mathbf{\%})\end{array}$ & $\begin{array}{l}\text { Gardnerella } \\
\mathbf{n}(\mathbf{\%})\end{array}$ & $\begin{array}{l}\text { Tricomonas } \\
\mathbf{n}(\mathbf{\%})\end{array}$ \\
\hline $\mathbf{2 0 1 3}$ & $380(35.5)$ & $226(36.5)$ & $57(23.2)$ & $285(71.4)$ & $24(36.9)$ & $53(34.4)$ & $3(18.8)$ \\
\hline $\mathbf{2 0 1 4}$ & $403(37.6)$ & $224(36.1)$ & $123(50.0)$ & $60(15.0)$ & $20(30.8)$ & $72(46.8)$ & $5(31.2)$ \\
\hline $\mathbf{2 0 1 5}$ & $181(16.9)$ & $102(16.5)$ & $41(16.7)$ & $36(9.0)$ & $10(15.4)$ & $18(11.7)$ & $2(12.5)$ \\
\hline $\mathbf{2 0 1 6}$ & $107(10.0)$ & $68(11.0)$ & $25(10.2)$ & $18(4.5)$ & $11(16.9)$ & $11(7.1)$ & $6(37.5)$ \\
\hline Total & $\mathbf{1 0 7 1 ( 1 0 0 )}$ & $\mathbf{6 2 0 ( 1 0 0 . 0 )}$ & $\mathbf{2 4 6 ( 1 0 0 . 0 )}$ & $\mathbf{3 9 9 ( 1 0 0 . 0 )}$ & $\mathbf{6 5 ( 1 0 0 . 0 )}$ & $\mathbf{1 5 4 ( 1 0 0 . 0 )}$ & $\mathbf{1 6 ( 1 0 0 . 0 )}$ \\
\hline p-value & & 0.415 & $\mathbf{0 . 0 0 0 1}$ & $\mathbf{0 . 0 0 0 1}$ & 0.228 & $\mathbf{0 . 0 3 9}$ & $\mathbf{0 . 0 0 3}$ \\
\hline
\end{tabular}


Mendes, et al. [22] as well, who found 21 to 30 years old. This study is according to Adad, et al. [23], who found Candida sp. as the second most prevalent infection in women.

Trichomoniasis is caused by Trichomonas vaginalis, and it is considered a non-viral sexually transmitted disease (STD) most common in the world, with 250 to 350 million new cases identified each year [24]. Among the evaluated women, there were identified 16 cases (1.5\%), different of other studies, where De Carli and Machado [25] evaluated 500 women and found a prevalence of $29.4 \%$. Adad, et al. [23] studied trichomoniasis in 20,356 patients, and found $10 \%, 17.3 \%, 9.8 \%$ and $3.4 \%$ during the years of 1968, 1978, 1988 and 1998 respectively.

Rosset, et al. [26] correlated trichomoniasis with the herpes genital virus showing that the inflammatory response induced by Trichomonas vaginalis leads to an infiltration of defence cells (leucocytes, lymphocytes and macrophages) in the uterine mucosa, causing hemorrhagic spots, allowing the straight access for the virus. Lupi [27] described that its transmission occurs through mucous surfaces and it is easier when the immunologic system is suppressed.

In this study, we identified $57.9 \%$ of lactobacillus, $23 \%$ of bacillus and $37.3 \%$ of coccus. Campos, et al. [28] analyzed cytologic exams and identified the following prevalence: $35.2 \%$ of lactobacillus, $56.8 \%$ of bacillus and $42.2 \%$ of coccus, saying that variety of bacteria are found in asymptomatic women normally, being part of the flora. Silva, et al. [29] as well noticed at their study that microbiological agents very common in the cervix are bacillus $(52.8 \%)$, coccus $(45.5 \%)$ and lactobacillus (32.6\%).

Looking at the age range of the participants, we noticed that 19 cytopathologic exams were performed in women under 14-years-old. According to Medeiros, et al. [30] the early initiation at sexual life increases the risk of cervical cancer, because the cervical epithelium transformation zone is more proliferative during the puberty and adolescence, being susceptible to modifications mainly by HPV. Studies performed by Wang and Song [31] and Lu and Cols [32], reported that vaginal microbiota imbalance is positively correlated with HPV infection, thus vaginal microbiota changes can predict the development and prognosis of cervical lesions, and HPV outcome.

\section{Conclusion}

The prevalence shows that measures should be taken in order to follow and orientation about the infections prevention.

We identified the necessity of encouraging third age women to conduct cytopathologic exam periodically and annually, because only 127 women over 60-years-old were submitted to the exam during a four-year period.
The relevant register of Gardnerella vaginalis and Candida sp. highlights the necessity of adopting a clinical approach in order to improve the women well-being. About the Trichomonas vaginalis, even with low numbers compared to other studies, it is extremely important the counseling by health professionals in order to clarify doubts about the prevention, transmission and treatment.

However, this study was limited about the information related to: education, use of contraceptive use, number of sexual partners, number of children and miscarriage, sociodemographic profile, smoking and use of alcohol, and the treatment that was provided if any for those women that had pathogenic vaginal microorganisms detected, due to a lack of registration at the used resource.

It is important to say that only two cases of NIC I were found, so the prevalence could not be discussed, as well possible mistakes at sampling and diagnostic process. Besides, it is important to realize more studies about this theme, in order to scientifically help other intervention proposals to prevent cervix cancer from vaginal infections and STDs.

\section{References}

1. Parkin DM, Bray F, Devesa SS (2001) Cancer burden in the year 2000. The global picture. Eur J Cancer 37: 44-66.

2. Rocha AS, Schaefer PG, Edelweiss MIA (2015) Cervical Cytological Screening: Assessment of the FournierVR Self-Sampling Device in a Cervical Pathology Outpatient Clinic. Diagnostic Cytopathology 43: 802-809.

3. Silva B, Santos RNLC, Ribeiro FF, Anjos UU, Ribeiro KS, et al. (2014) Prevention of cervical cancer and the expansion of the risk age. Revista de Enfermagem UFPE 8: 14821490.

4. Instituto Nacional de Cancer (2016) Estimative. Incidence of Cancer in Brazil, Rio de Janeiro.

5. Ramos AS, Palha RF, Junior ML, Anna SC, Lenza NL, et al. (2006) Pap smear realization profile of women between 40 and 49 years registered at a family health center. Rev Latino-Am Enfermagem 14: 170-174.

6. Ribeiro AA (2007) Microbiological agents in cytopathology testing: A prevalence study. Revista Brasileira de Analises Clinicas 39: 179-181.

7. Oliveira AB, Franca CA, Santos TB, Garcia MC, Tsutsumi $M Y$, et al. (2007) Prevalence of gardnerella and mobiluncus in vaginal cytology examinations in Tome-Avu - Para. Revista Paranaense de Medicina 21: 47-51.

8. Peixoto JV (2014) Candidiasis: a literature review. Brazilian Journal of Surgery and Clinical Research-BJSCR 8: 75-82.

9. Resador IJ, Santos AF (2015) Analysis of the vaginal microbiota of students from a higher education institution Araraquara: Changes detected and relation to periods of stress. Revista de Ciencias Farmaceuticas Basicas e Aplicadas 36: 59-64.

10. Sa M, Silva MT, Almeida D, Vieira B, Lima T, et al. (2015) Sexually transmitted diseases and risk factors in adolescent and young girls: Data from a youth attendance center. Nascer e Crescer 24: 64-66. 
11. Vasconcelos S, Martins L (2005) Correlation between microbiological alterations and the knowledge of alterations in the colpocitologyc exam by the women in Douradina city in 2004. Arquivo de Ciencias da Saude da UNIPAR 9: 167173.

12. Campos ACC (2012) Evaluation of cytokines in endocervical-vaginal secretion of patients with bacterial vaginosis, $84 \mathrm{f}$. Thesis (PhD in Health Science), Federal University of Goias, Goiania.

13. Abdalla DR, Simoens C, Bogers JP, Murta EF, Michelin MA (2015) Angiogenesis Markers in Gynecological Tumors and Patents for Anti-Angiogenic Approach: Review. Recent Pat Anticancer Drug Discov 10: 298-307.

14. Carvalho EEV, Salge AKM, Martins MG, Silveira CF, Estevam G, et al. (2015) Knowledge of University Students About Human Papillomavirus Infection And Relationship With Curricular Cycle. JCBS 1: 50-55.

15. Abdalla GK, Fajardo EF, Gomes BB, Bianco TM, Salge AK, et al. (2017) Analysis of Knowledge Level in Brazilian Students about Human Papillomavirus Infection and Development of Penile Cancer. Asian Pac J Cancer Prev 18: 1371-1376.

16. Biswala BM, Singh KKB, Ismail MB, Jalal MIB, Safruddin EIS (2014) Current Concept of Bacterial Vaginosis in Cervical Cancer. J Clin Gynecol Obstet 3: 1-7.

17. Coser S, Rodrigues A (2016) Prevalence of genital infections in women assisted in a clinical analysis laboratory in Caxias do Sul. Ciencia em Movimento 36.

18. Silveira ACO, Souza HAP, Albini CAA (2010) The Gardnerella vaginalis and the urinary tract infections. Jornal Brasileiro de Patologia e Medicina Laboratorial 46: 295-300.

19. Mitra A, Maclntyre DA, Marchesi JR, Yun S Lee, Phillip R Bennett, et al. (2016) The vaginal microbiota, human papillomavirus infection and cervical intraepithelial neoplasia: What do we know and where are we going next? Microbiome 4: 58.

20. Ribeiro KAAR, Moura RCM, Oliveira SMS (2011) Incidencia de candidiase vaginal em dois laboratorios de referencia no municipio de Santarem- PA no periodo de janeiro de 2009 a junho de 2011. Revista Perspectiva Amazonica 3: 86-96.

21. Boatto HF, Moraes MR, Machado AP, Girao MJ, Fischma O (2007) Relationship of laboratory results with clinical signs and symptoms of patients with vulvovaginal candidiasis and the significance of the sexual partners for the maintenance of the infection. Revista Brasileira de Ginecologia e Obstetricia 29: 80-84.

22. Mendes CL (2005) Prevalence of Candida sp. In vaginal infections. Revista News Lab 68: 104-112.

23. Adad SJ, de Lima RV, Sawan ZT, Silva ML, de Souza MA, et al. (2001) Frequency of Trichomonas vaginalis, Candida sp and Gardnerella vaginalis in cervical-vaginal smears infour diferente decades. Revista Paulista de medicina 5: 119-125.

24. Kissinger P (2015) Trichomonas vaginalis: A review of epidemiologic, clinical and treatment issues. BMC Infect Dis 15: 307.

25. De Carli GA, Machado B (1975) Epidemiology and laboratory diagnosis of Trichomonas vaginalis. Rev Microbiol 4: 33-36.

26. Rosset I, Tasca T, Tessele PM, Carli GA (2002) Scanning electron microscopy in the investigation on the in vitro hemolytic activity of Tricomonas vaginalis. Parasitol Res 88: 356-359.

27. Lupi O (2003) Antiherpetic immunoprophylaxy with genetically modified virus: DISC vaccine. An Bras Dermatol 78: 345-353.

28. Campos AC, Murta EF, Michelin MA, Reis C (2012) Evaluation of Cytokines in Endocervical Secretion and Vaginal $\mathrm{pH}$ from Women with Bacterial Vaginosis or Human Papillomavirus. ISRN Obstet Gynecol.

29. Silva DSM, Silva AMN, Brito LM, Lisboa Gomes SR, Nascimento MD, et al. (2014) Cervical cancer screening in the State of Maranhao, Brazil. Cienc saude coletiva 9: 11631170.

30. Medeiros VCR, Medeiros RC, Moraes L (2005) Uterine cervix cancer: analysis of epidemiological and cytopathological in the state of Rio Grande do Norte. Rev Bras Anal Clin. 37: 227-231.

31. Wang PC, Song JH (2017) The correlation between vaginal microecological changes and HPV outcome in patients with cervical lesions in the Inner Mongolia area of China. Int $\mathrm{J}$ Clin Exp Med 10: 5711-5720.

32. Lu H, Jiang PC, Zhang XD, Hou WJ, Weil ZH, et al. (2015) Characteristics of bacterial vaginosis infection in cervical lesions with high risk human papillomavirus infection. Int $\mathrm{J}$ Clin Exp Med 8: 21080-21088. 